\title{
Review Article \\ Reuse of Clay Brick Waste in Mortar and Concrete
}

\author{
Lihua Zhu $\mathbb{D}^{1,2}$ and Zengmei Zhu ${ }^{1,2}$ \\ ${ }^{1}$ State Key Laboratory of Green Building in Western China, Xi'an University of Architecture \& Technology, Xi'an 710055, China \\ ${ }^{2}$ School of Civil Engineering, Xi'an University of Architecture \& Technology, Xi'an 710055, China
}

Correspondence should be addressed to Lihua Zhu; zhulihuaxa@163.com

Received 18 April 2020; Revised 8 June 2020; Accepted 16 June 2020; Published 3 July 2020

Academic Editor: J. M. P. Q. Delgado

Copyright (c) 2020 Lihua Zhu and Zengmei Zhu. This is an open access article distributed under the Creative Commons Attribution License, which permits unrestricted use, distribution, and reproduction in any medium, provided the original work is properly cited.

\begin{abstract}
The application of recycled clay brick can not only solve the disposal problem of demolished solid waste but also reduce ecological environment damage caused by the excessive development of resources. Clay brick powder (CBP) exhibits pozzolanic activity and can be used as cement replacement. Recycled clay brick aggregate (RBA) can be used to substitute natural coarse aggregate. Recycled clay brick aggregate concrete (RBAC) can attain suitable strength and be used in the production of medium- and lowstrength concrete. Clay brick waste as potential partial cement and aggregate replacement material is reviewed herein. Performances in terms of mechanical and durability-related properties of mortar and concrete are discussed. Understanding the properties of clay bricks is crucial to further research and applications.
\end{abstract}

\section{Introduction}

Clay brick structures are widely used worldwide. In the early days of the founding of China, many clay brick structures were built. Over time, many buildings reached their design lifetime or became defective because of the use of faulty construction or inappropriate materials. Additionally, frequent earthquakes destroyed many buildings and produced a large amount of waste. Owing to the needs of urban development and reconstruction, old buildings had to be demolished, thereby resulting in the accumulation of clay brick waste $[1,2]$ (Figure 1). China produced approximately 15.5 million tonnes of construction waste each year, primarily concrete and brick. According to the report of the European Union in 2011, approximately 1 billion tonnes of construction and demolition waste (CDW) were produced in the European Union each year, which contained plenty of bricks [3]. Additionally, clay brick waste from demolished brick walls accounted for approximately $54 \%$ of construction and demolition waste in Spain [4]. In the capital of Valle del Cauca, Cali, an average volume of $1900 \mathrm{~m}^{3}$ of CDW was produced by construction companies and public construction [5]. Furthermore, private constructions and renovation projects generated $580 \mathrm{~m}^{3}$ of CDW [5].
The main method to handle CDW is through landfill or reclamation sites. The foundation of a landfill is of poor quality. Additionally, using landfill or reclamation sites is an expensive approach. It costs approximately $\$ 21 /$ ton to recycle one ton of concrete, brick, and masonry, while it costs approximately $\$ 136 /$ ton to landfill the same material [6]. In addition, the distance between demolition sites and disposal areas is becoming larger, and the transportation costs are becoming higher. As landfills and reclamation areas are limited, the landfill of waste clay bricks occupies valuable land resources and damages the soil structure, resulting in a poor grain yield. Waste storage and disposal is becoming a serious environmental problem, especially in most cities lacking disposal sites. By recycling construction waste, the amount of waste to be transferred to landfills would be significantly reduced [6].

The production of concrete and mortar has consumed a large number of nonrenewable resources and caused serious environmental pollution. Concrete is made of sand, gravel, cement, and water, which are difficult to obtain. At the world level, civil engineering and construction consumed $60 \%$ of raw materials extracted from the lithosphere [7]. Furthermore, an increase in population resulted in an increase in construction activity and the consumption of natural 


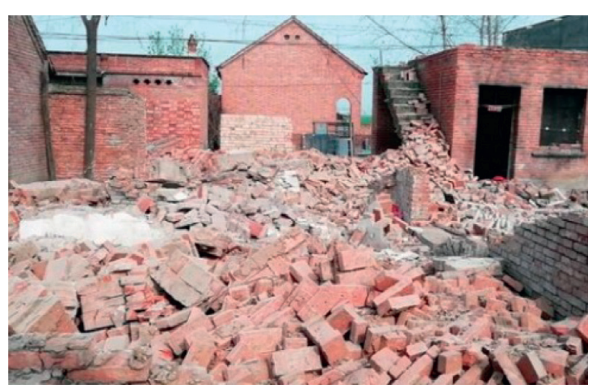

(a)

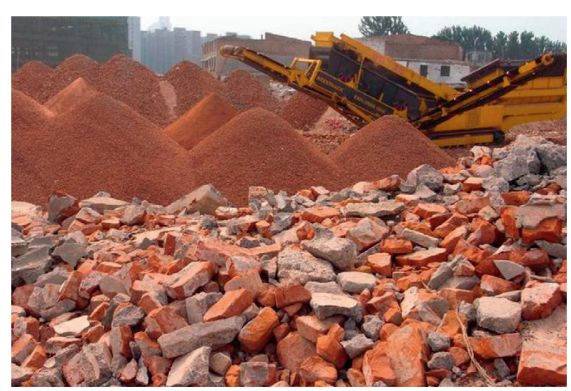

(b)

FIGURE 1: Clay bricks waste: (a) construction and demolition waste; (b) processing brick aggregate (colour figure can be viewed at http://3g. 163.com/dy/article/DEDFJ5M60520EK8D.html).

resources. In areas lacking high-quality rocks or gravel, it would not be economical to import aggregates. In many urban areas, good natural aggregates are scarce, sand and stone resources have gradually exhausted, and mining has become more difficult. Meanwhile, the production of cement is not environment-friendly. As an important raw material of concrete, cement will produce plenty of dust and carbon dioxide during its production [8]. With the current technology, the production of 1 ton of cement consumes 1.7 tonnes of raw materials, approximately $7000 \mathrm{MJ}$ of electricity and fuel energy [9], and 0.75 tonnes of carbon dioxide, and 12 kilograms of sulphur dioxide and dust [10]. In China, 2.5 billion tonnes of cement, accounting for approximately $60 \%$ of the world cement production, were produced in 2014 $[11,12]$.

Clay brick wastes have a high resource value and many countries are reusing them for many applications in construction activities. A waste framework for moving toward a European recycling society with a high level of resource efficiency was provided in the European Directive (2008/98/ EC) of 19 November 2008 [13]. The European Union has set a goal of recycling $70 \%$ of its construction waste by 2020 [14]. In Germany, Denmark, and Netherlands, reuse rates are approximately $80 \%$, compared with an average of $30 \%$ in other countries [15]. Although Germany first used crushed bricks in Portland cement to produce concrete products in 1860 [16], crushed brick as aggregate was significantly used in fresh concrete for reconstruction after the Second World War [17]. It was reported that 11.5 million $\mathrm{m}^{3}$ of crushed brick aggregates was used to build 175,000 dwelling units [18].

The concept of sustainable development includes energy conservation, environmental protection, and protection of nonrenewable natural resources. Because of limited landfill space and costly natural aggregates, the application prospect of crushed clay bricks as a new civil engineering material must be investigated. Waste reuse and recycling is a method of energy conservation in modern society. Reuse of clay bricks as aggregates not only reduces the problem of waste storage but also helps to preserve natural aggregate resources [19]. The use of waste clay bricks not only reduces the cost of site cleaning and disposal but also yields significant social and economic benefits.
To provide a reference for further research on waste clay bricks, the reuse of waste clay bricks in concrete engineering is summarised extensively. The mechanical properties and durability of mortar using clay brick waste as cement or sand are described, and the mechanical properties and durability of concrete containing RBA are summarised. The potential application of RBAC on structural members is discussed as well.

\section{Clay Brick Waste Used in Mortar}

Clay brick waste can be ground into tiny particles to be used in mortar. It can exist in two forms: CBP and fine aggregates. The former exhibits pozzolanic activity to yield a denser mixture, and the latter can be used as sand replacement. The mechanical and durability properties of mortar have been studied in previous studies.

2.1. Pozzolanic Activity of CBP. Several studies [20, 21] have determined that CBP is a pozzolanic material. Its pozzolanic activity is the result of the transformation of crystalline structures of clay silicates in amorphous compounds during the manufacture of bricks, where clay is exposed to high temperatures from $600^{\circ} \mathrm{C}$ to $1000^{\circ} \mathrm{C}$. The pozzolanic activity of CBP can be confirmed by microstructure characterisation. As shown in Figure 2, the CBP grain has a semioval shape and a semismooth surface, and it comprises morphologically irregular particles, which are mainly quartz and feldspar, the components required for the pozzolanic activity.

Generally, burned clay may not exhibit pozzolanic activity. Clay contains a high proportion of quartz and feldspar, which are crystalline minerals and do not produce active substances. Therefore, clay cannot be considered a pozzolan. However, if clay is exposed to a temperature of $600-1000^{\circ} \mathrm{C}$, the crystal structure of the silicate will often change into an amorphous compound reacting with lime at room temperature [22]. The assessment of pozzolanic activity is typically based on a strength activity index specified by ASTM C618, which limits the sum of silicon, ferric, and aluminium oxides to be at least $70 \%$ for pozzolans [23]. Plenty of studies have shown that those oxides of CBP were beyond $70 \%$ and exhibit high pozzolanic activity 


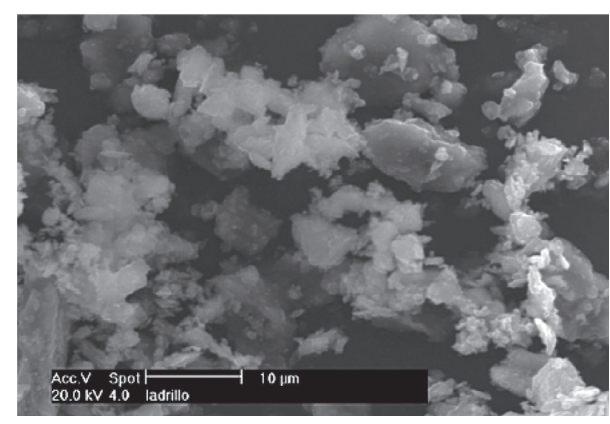

Figure 2: SEM micrograph of brick powder [21].

[20, 21, 23-40]. As shown in Table 1 , the sum of silicon, ferric, and aluminium oxide of CBP exceeded $70 \%$, which proved that CBP had high pozzolanic activity; these components will promote the formation of C-S-H (calcium silicate hydrates) or C-A-H (calcium aluminate hydrates) and thus affected the performance of mortar and concrete.

Pozzolanic activity refers to the ability of substances to react with calcium hydroxide to form hydration products at ordinary temperatures. The $\mathrm{pH}$ value of saturated calcium hydroxide solution is 12.45 at $25^{\circ} \mathrm{C}$. High concentrations of $\mathrm{OH}^{-}$ions can break bonds in silica, silicates, and aluminosilicates to generate simple ions [41, 42], according to the following chemical reaction:

$$
\begin{aligned}
& \equiv \mathrm{Si}-\mathrm{O}-\mathrm{Si} \equiv+8 \mathrm{OH}^{-} \longrightarrow 2\left[\mathrm{SiO}(\mathrm{OH})_{3}\right]^{-}+\mathrm{H}_{2} \mathrm{O} \\
& \equiv \mathrm{Si}-\mathrm{O}-\mathrm{Al} \equiv+7 \mathrm{OH}^{-} \longrightarrow\left[\mathrm{SiO}(\mathrm{OH})_{3}\right]^{-}+\left[\mathrm{Al}(\mathrm{OH})_{4}\right]^{-}
\end{aligned}
$$

The resulting silicate and aluminate ions accompany $\mathrm{Ca}^{2+}$ ions form C-S-H (calcium silicate hydrates) or C-A-H (calcium aluminate hydrates) [43, 44]. As the dissolution rate of silicate is more rapid than that of aluminate and the formation of calcium aluminate requires a higher concentration of calcium ions, first, CSH gels would appear on the particles of pozzolans, and then hexagonal sheets of calcium aluminates precipitate on the surface of the CSH gels.

Studies have shown that the pozzolanic activity of CBP increased with the content in the amorphous phase. Furthermore, the larger the specific surface area is, the smaller the particles are and the higher the pozzolanic activity is, because the powder in the pozzolanic reaction has a large reaction surface [27]. Moreover, CBP presented a higher specific surface than cement and exhibited high pozzolanic activity [20].

2.2. Mechanical Properties of Mortars with Clay Brick Waste. $\mathrm{CBP}$ can be considered as a promising filler that reduces the effect of the greater shrinkage phenomenon, which is likely produced by a higher pore refinement owing to the development of pozzolanic activity of CBP. Several studies $[21,27,28,45]$ have shown that the microstructure was more refined for mortars with CBP. Moreover, the microstructure became more refined and the percentage of finer pores gradually increased over time. CBP improves the structure of mortar and reduces the size and number of pores in it, resulting in a stronger and denser hardened paste. Aliabdo et al. [23] studied the pore structure of paste specimens with $\mathrm{CBP}$. They discovered that the pozzolanic reactivity of CBP and possibly the rehydration of unhydrated cement particles in attached mortar improved the density of the matrix and refined the pore structure. The pore structure of the investigated paste specimens is displayed in Figure 3, and the sample containing $25 \%$ CBP has the smallest pore diameter and the best pore structure. The mortar with $\mathrm{CBP}$ has a higher degree of microstructure refinement, which may be related to the combined action of the additional reinforcement phase formed by the products of pozzolanic reaction of CBP and the filling effect of this additive. Furthermore, the addition of CBP affects the proportion of pores in the mortar. With the partial replacement of cement by $\mathrm{CBP}$, the proportion of macropores reduced and the proportion of mesopores increased [26]. Although the study demonstrated the filling effect of CBP, Gonçalves et al. [26] reported that the packing density did not change significantly with the replacement of cement by CBP. They concluded that this might be attributed to the similarity between the particle size distributions of CBP and Portland cement, resulting in no change in the packing density. Furthermore, it is also possible that the product of pozzolanic activity of CBP makes up for the weight loss caused by CBP replacing Portland cement.

In addition, water/cement $(\mathrm{w} / \mathrm{c})$ ratio affects the density of mortar containing CBP. Under different $w / c$ ratios, the effect of replacing cement with CBP on density is different. Toledo Filho et al. [25] discovered that the mixes of series M1 $(\mathrm{w} / \mathrm{c}=0.40)$ yielded porosity values that were $28 \%$ to $35 \%$ lower than those observed for mixes of series M2 (w/ $c=0.50$ ).

Alkaline activation can transform aluminosilicate materials into more compact binding materials. Robayo et al. [29] discovered that the addition of ordinary Portland cement and $\mathrm{Na}_{2} \mathrm{SiO}_{3}$ to the mixture promoted the dissolution of some phases in clay brick waste and increased alkaliactivating processes, which improved the mechanical behaviour. Reig et al. [30] demonstrated that CBP could form alkali-activated cement pastes and mortars using $\mathrm{NaOH}$ and sodium silicate solution as activators. The compressive strength of the mortar was approximately $30 \mathrm{MPa}$ with a w/b ratio of 0.45 , which proved that it was feasible to use CBP in cement after $\mathrm{CBP}$ was activated by $\mathrm{NaOH}$ and sodium silicate solution. Additionally, Rovnaník et al. [31] studied alkali-activated CBP and discovered that the specimens exhibited a less compact structure with more pores located between sharp-edged grains, and geopolymers containing alkali-activated CBP exhibited lower flexural and compressive strengths.

Some previous studies reported that using CBP as cement addition improved the compressive strength of mortar. The pozzolanic activity of these CBP may contribute to the higher initial and final strengths of the mortars containing them. The chemical composition of CBP also explained the mechanism of this phenomenon that the presence of CBP provided to continue strength gain of mortars up to the 90th day since CBP activated hydrations of silica based 
TABLe 1: Composition of CBP.

\begin{tabular}{|c|c|c|c|c|c|c|c|c|c|c|c|}
\hline & & & & Chem & compc & on (\%) & & & & & Reference \\
\hline $\mathrm{SiO}_{2}$ & $\mathrm{Al}_{2} \mathrm{O}_{3}$ & $\mathrm{Fe}_{2} \mathrm{O}_{3}$ & $\mathrm{CaO}$ & $\mathrm{SO}_{3}$ & $\mathrm{MgO}$ & $\mathrm{Na}_{2} \mathrm{O}$ & $\mathrm{K}_{2} \mathrm{O}$ & $\mathrm{TiO}_{2}$ & $\mathrm{MnO}$ & $\mathrm{P}_{2} \mathrm{O}_{5}$ & Kelerence \\
\hline 41.47 & 39.05 & 12.73 & 0.63 & 1.59 & - & - & 2.81 & 1.03 & - & - & {$[20]$} \\
\hline 41.47 & 39.05 & 12.73 & 0.63 & 1.59 & - & - & 2.81 & 1.03 & - & - & [21] \\
\hline 54.2 & 15.4 & 7.6 & 6.8 & 1.1 & 2.5 & - & - & - & - & - & [23] \\
\hline 39.55 & 15.71 & 14.05 & 12.88 & 0.48 & 3.29 & - & 1.98 & - & - & - & [24] \\
\hline 63.89 & 25.49 & 7.73 & 0.29 & - & 0.04 & Traces & 0.95 & - & - & - & [25] \\
\hline 63.89 & 25.49 & 7.73 & 0.29 & - & 0.04 & Traces & 0.95 & Traces & Traces & - & [26] \\
\hline 58.5 & 15.61 & 3.52 & 13.79 & 2.04 & 2.07 & 0.38 & 2.81 & 0.46 & 0.03 & 0.15 & [27] \\
\hline 58.12 & 15.25 & 3.26 & 15.1 & 2 & 1.87 & 0.38 & 2.84 & 0.41 & 0.03 & 0.18 & \\
\hline 58.34 & 15.14 & 3.22 & 14.1 & 2.02 & 2.22 & 0.39 & 2.82 & 0.49 & 0.04 & 0.17 & \\
\hline 59.12 & 15.19 & 4.81 & 10.15 & 1.33 & 4.28 & 1.39 & 3.07 & 0.4 & 0.05 & 0.16 & \\
\hline 58.13 & 15.24 & 4.63 & 10.57 & 1.42 & 4.32 & 1.42 & 3.08 & 0.39 & 0.05 & 0.16 & \\
\hline 58.87 & 15.1 & 4.61 & 10.24 & 1.23 & 4.28 & 1.44 & 3.06 & 0.4 & 0.05 & 0.16 & \\
\hline 77.43 & 9.27 & 3.9 & 2.89 & 0.11 & 1.36 & 0.8 & 2.26 & 0.62 & 0.06 & - & [28] \\
\hline 73.83 & 12.94 & 5.52 & 1.67 & 0.12 & 1.36 & 0.9 & 2.18 & 0.84 & 0.08 & - & \\
\hline 77.52 & 9.85 & 4.4 & 2.03 & 0.07 & 1.15 & 0.84 & 2.28 & 0.63 & 0.06 & - & \\
\hline 72.83 & 12.01 & 5.73 & 2.95 & 0.09 & 1.7 & 0.99 & 1.94 & 0.72 & 0.09 & - & \\
\hline 65.92 & 20.08 & 9.1 & 0.73 & - & 0.86 & 0.44 & 0.97 & 1.09 & - & - & [29] \\
\hline 49.9 & 16.6 & 6.5 & 9.7 & 3.3 & 5.5 & 0.5 & 4.4 & 0.8 & 0.1 & 0.2 & {$[30]$} \\
\hline 57.67 & 14.91 & 5.02 & 9.81 & 1.86 & 3.74 & 1.45 & 3.2 & - & - & - & [31] \\
\hline 54.83 & 19.05 & 6 & 9.39 & 2.9 & 1.77 & 0.5 & 3.15 & 0.97 & - & 0.2 & [32] \\
\hline 69.99 & 10.62 & 4.02 & 8.86 & 0.038 & 1.39 & 1.02 & 2.61 & 0.55 & - & 0.11 & \\
\hline 68.79 & 15.23 & 6.28 & 1.79 & 0.127 & 2.02 & 0.26 & 3.71 & 0.85 & - & 0.07 & \\
\hline 72.75 & 15.89 & 4.97 & 0.87 & 0.07 & 1.2 & 0.27 & 2.17 & 0.84 & - & 0.1 & \\
\hline 67.58 & 18.94 & 8.084 & 0.948 & 0.13 & 0.719 & 0.246 & 1.884 & 1.06 & - & - & [33] \\
\hline 69.26 & 14.17 & 6.3 & 4.28 & 0.02 & 2.25 & 0.28 & 1.34 & - & - & - & [34] \\
\hline 53.8 & 14.1 & 12.1 & 9.2 & - & 8.9 & 1.3 & - & - & - & - & [35] \\
\hline 69.43 & 17.29 & 6.4 & 0.51 & 2.54 & 1.14 & - & - & - & - & - & [36] \\
\hline 67.9 & 15.2 & 5.1 & 0.6 & - & 1.2 & 0.8 & 1.5 & 0.8 & 0.1 & - & [37] \\
\hline 75.06 & 14.25 & 5.61 & 1.3 & 0.7 & 1.35 & 0.19 & 0.08 & - & - & - & [38] \\
\hline 52 & 40 & 1.5 & 0.5 & - & 0.3 & - & - & 5 & & & [39] \\
\hline 50.91 & 15.29 & 8.97 & 12.7 & 0.2 & 4.06 & 0.83 & 0.76 & - & - & - & [40] \\
\hline
\end{tabular}

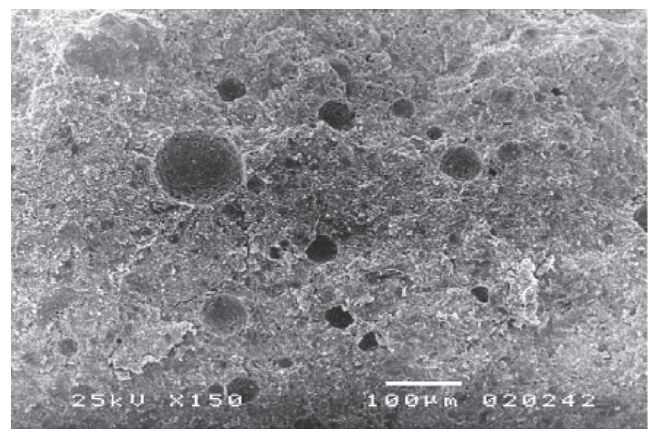

(a)

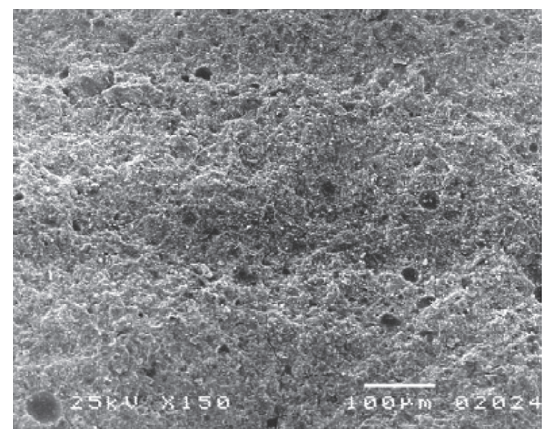

(b)

Figure 3: Microstructure of paste samples. (a) Pore structure of 15\% CBP paste and (b) pore structure of 25\% CBP paste [23].

compounds in cement pastes. With the increase in the percentage of additions, the compressive strength increases [24]. The compressive strength of mortar also increases with the age and fineness of CBP. The finer the particle size of the CBP is, the denser the microstructure of the paste matrix is and the higher the compressive strength of the pastes is $[25,32]$. Additionally, a high curing temperature can improve the hydration activity of CBP efficiently [33]. O'Farrell et al. [32] confirmed an important connection between compressive strength and threshold radius of mortar. For threshold radii down to $0.1 \mu \mathrm{m}$, compressive strength was not very sensitive to threshold radius, and it had only a small increase for a large decrease in threshold radius. However, when the threshold radius decreased below $0.1 \mu \mathrm{m}$, the strength increased significantly with a small decrease in the threshold radius. It showed that the compressive strength 
increased with the increase in pore fineness and decrease in pore volume, and it also showed the effect of this additional $\mathrm{C}-\mathrm{S}-\mathrm{H}$ gel on the development of compressive strength.

Furthermore, the substitution ratio of CBP significantly affects the strength of mortar. Ortega et al. [21] revealed that the effect of pozzolanic activity was more pronounced for mortars with $10 \%$ CBP compared with those having $20 \%$ of this addition. This may be attributed to the former containing more clinker; therefore, at the same hardening ages, it was expected that a large amount of portandite had been formed for $10 \%$ CBP specimens compared to $20 \%$ specimens. Meanwhile, in the study of Liu et al. [33], the substitution ratio indicated by intensity change should not exceed $15 \%$. Moreover, the substitution of high amounts of CBP will reduce the compressive strength of mortar significantly; when the replacement rate reaches $25 \%$, the strength of the mortar will decrease by $25.2 \%$ [23]. This may be due to the following: pozzolanic activity produces metastable C-A-H partially; the metastable C-A-H can transform into a stable hydrogarnet with a variable composition at higher temperatures or with a longer curing time [30], and the hydrogarnet results in the reduced volume, compactness, and strength of mortars [46].

Although the replacement of CBP in mortar yielded reduced compressive strength, studies by Ortega et al. [21] confirmed that the addition of CBP did not reduce the compressive strength of the mortars, which satisfied the requirements of corresponding standards. It showed the beneficial effect of pozzolanic activity and filling effect of CBP in the performance of mortars. The compressive strength of all the studied mortars increased with hardening age, and the value for BP10 (10\% brick powder) specimens was slightly higher than those noted for CEM I (a commercial ordinary Portland cement) ones at 400 days. Moreover, the flexural strength was slightly greater for mortars with CBP in comparison with CEM I ones over the 400-day period. Similarly, Boukour and Benmalek [34] discovered that CBP fillers induced only a small decrease in flexural and compressive strength with the level (2.5\%, 5.0\%, $7.5 \%$, and $10 \%$ ) used. The rigidity of the replaced natural sand portion might have compensated for the pozzolanic activity provided by the fine portion of the CBP filler. Moreover, Toledo Filho et al. [25] discovered that the addition of CBP had almost no effect on the compressive strength and elastic modulus until the percentage of $20 \%$ cement replacement. However, under a high w/c ratio, the strength and elastic modulus of mortar will decrease with the increase in CBP.

Studies regarding clay brick waste as fine aggregate in mortar have been reported. Bektas et al. [47] demonstrated that the high water absorption capacity of clay brick significantly affected the flow of mortar. However, even $30 \%$ of the brick mixture demonstrated sufficient workability and good consolidation with the given mixture proportions. This confirmed that brick aggregates did not reduce the strength of mortar with the levels used. Moreover, Mobili et al. [48] discovered that mortar with RBAs exhibited the highest amount of water absorbed by the capillary action.
2.3. Durability of Mortars with Clay Brick Waste. Durability is an important property of mortar. Water capillary absorption is essential for determining the durability of construction materials. Some findings on the addition of CBP revealed that CBP with low substitution rate (less than 20\%) could make a higher difficulty of water ingress in the mortars containing CBP $[25,26]$. This behaviour may be related to more refined porous structures, which reduced water penetration. The addition of CBP improved the sulphate resistance of cement mortar. An appropriate replacement for providing high sulphate resistance appears to be approximately $15 \%$ $[35,48,49]$. Additionally, the use of CBP significantly reduced the penetration rate of chloride ions, which is a typical cause of steel corrosion in mortars; the mechanism that can explain this phenomenon is that CBP promotes the formation of additional hydrates, which can reduce the permeability and increase the densification of the materials making the penetration of chloride ions much more difficult $[21,25$, $26,45,50]$. Additionally, Aliabdo et al. [23] found that the incorporation of CBP reduced the weight loss of mortar under high temperature. The reference specimens (without CBP) had highest weight loss attribute to the dehydration of C-S-H and ettringite contents and calcium hydroxide, while the pozzolanic reactivity of mortar with CBP consumed much more of these substances, resulting in lower weight loss; it can be concluded that the replacement of cement by CBP may result in a higher fire resistance of the mortar.

With regard to clay brick fine aggregates in mortar, Bektas et al. [47] studied the freeze-thaw process of mortar with fine brick aggregates; they concluded that the use of fine brick aggregates reduced the freeze-thaw expansion of mortar. As the aggregates contained more air bubbles preventing freeze-thaw-associated cracking, the pressure caused by ice formation and water flow was relieved, and the water flow paths were cut; in other words, tightly distributed air void structure provided space for expansive mechanisms.

In terms of drying shrinkage, Bektas et al. [47] reported a reduction in drying shrinkage after incorporating $20 \%$ recycled brick as fine aggregate. This was because additional water stored in the brick aggregate maintained plenty of moisture during hydration. Furthermore, they observed the effect of brick aggregates on the expansion of mortar immersed in $\mathrm{NaOH}$ solution and water. As brick aggregates are abundant in silica in nature, the possible formation of ASR can increase expansion and subsequent cracking. Similarly, Bektaş [51] investigated the ASR susceptibility of fine RBAs, and he concluded that ASR occurred in the form of reaction product of mortar bars, and the mortar expansion rate was proportional to the content of CBP.

\section{Clay Brick Waste Used in Concrete}

To reduce resource wastage, recycled clay brick was considered as an aggregate substitute in concrete. The physical properties of RBAs have been studied. As a mix design is key in RBAC, it was also studied. Additionally, some researchers have studied the mechanical properties and durability of RBAC. 
3.1. Physical Properties of RBA. Brick aggregates exhibit a higher porosity and absorption than natural aggregates. The density of RBAC decreases with increasing brick content [52-54]. The apparent density and bulk density of recycled clay brick as aggregates are lower than those of natural aggregates, and the water absorption rate and crushing index are higher than those of natural aggregates $[36,48,55]$. As the RBA particles were angular in shape, they bonded well with cement [52]. The strength of RBA has a greater effect on the strength of concrete. The higher the strength of RBAs is, the higher the strength of RBAC is [54,56,57]. The microscopic images of the cut surface of concrete with natural and brick aggregates are shown in Figure 4. From the visual observation of the concrete surface, compared with natural aggregates, the brick aggregates had more pores in their structure [36].

3.2. Mix Design of RBAC. Owing to the porous nature of RBAs, the change in water demand and the adjustment of the $\mathrm{w} / \mathrm{c}$ ratio should be considered in the mixing design $[52,58]$. Porous RBAs may consume water for mixing concrete, which affects the workability of concrete. Hence, prewetting brick aggregates are recommended to avoid this problem [23]. Additionally, the RBAs must be in the saturated surface-dry condition before mixing, because additional water may affect the workability of RBAC [52]. Adamson et al. [36] studied the workability of concrete with RBAs; they discovered that the workability of concrete increased with the amount of coarse aggregates when the w/c ratio was constant. This may be owing to the higher porosity of the brick, which can hold more water and hence improve the workability of concrete.

The performance of RBAC is affected by the w/c ratio, sand ratio, and average particle size of brick [36, 59-62]. Moreover, the replacement level of RBAs significantly affected the properties of RBAC [59]. Coarse aggregates with flat gradation can yield more uniform aggregate particle sizes, which would be beneficial for concrete performance $[36,60]$. The mechanical properties of RBAC degraded significantly with the increasing crushing index of recycled aggregates; however, the effects of increasing the crushing index on the permeability coefficient and total void ratio of RBAC can be ignored [61]. Some researchers have studied the mix design of RBAC using different methods. Ge et al. [62] adopted the orthogonal design method and obtained the optimal concrete mix in terms of compressive strength, flexural strength, and static elasticity modulus. Similar to normal concrete, the $\mathrm{w} / \mathrm{c}$ ratio was the most significant factor affecting the mechanical properties of concrete containing CBP. Šipoš et al. [59] used neural network modelling to study the mix design of RBAC; they discovered that compressive strength could be affected significantly by aggregate size (fine or coarse): the compressive strength value of fine aggregates was lower than that of coarse aggregates.

RBAs from different sources exhibit different properties; therefore, the optimal replacement rate of RBAs varies with the strength of RBAs and cannot be unified. Zhang and Zong
[58] suggested that $30 \%$ was an appropriate replacement level of coarse aggregates. Cachim [63] revealed that crushed bricks could be replaced by natural aggregate substitutes by up to $15 \%$ without strength reduction. When the replacement rate of RBA is $30 \%$, the concrete properties will be reduced (up to $20 \%$, depending on the brick type).

As the RBA exhibited lower strength, some methods were used to improve the strength of RBAC during the mix design. Adding additives can improve some properties of the specimens [64]. The use of an air-entraining admixture and superplasticiser can improve workability during mixing $[52,60]$. The performance of concrete can be partially improved by the appropriate amount of CBP $[45,62]$. The strength gain could be due to an increase in $\mathrm{SiO}_{2}$, which had a favourable effect on the formation of $\mathrm{CSH}$ gels as a result of pozzolanic reactions [23, 32, $34,65]$. Additionally, the mixed use of CBP and RBA could yield better RBAC performances [48, 59], likely because the fine RBA particles formed a compact and dense ITZ of mortar and filled the pores of RBAC. Manzur et al. [66] found that the corrosion susceptibility of concrete increased with the increase of water-cement ratio; moreover, a concrete mix with higher compressive strength was beneficial to concrete corrosion resistance, because it meant that the concrete will have a greater density and a lower permeability, resulting in less chloride ions entering. In addition, fibre can effectively inhibit the development of cracks and improve the toughness and deformation capacity of concrete [64].

3.3. Mechanical Properties of RBAC. The porosity of RBA increases the porosity of concrete, and it may increase the water absorption and reduce the strength properties of concrete [35]. The increase in water absorption of brick aggregates results in an increase in concrete water permeability. Moreover, the water permeability coefficient of RBAC and the compressive strength of RBA exhibit a linear relationship. The water permeability of RBAC decreased as the compressive strength of RBA increased [54,67]. Aliabdo et al. [23] studied the relationship between compressive strength and porosity, and they discovered that increased porosity was crucial in reducing the strength of concrete.

Additionally, the mechanical properties of RBAC and the maximum aggregate size (MAS) were correlated. Uddin et al. [68] reported the effects of MAS on RBAC. They revealed that the effect of cement content on compressive strength was more significant when the coarse aggregate MAS was smaller. Mohammed and Mahmood [69] reported that ultrasonic pulse velocity (UPV) increased with the maximum aggregate size. As the compressive strength and Young's modulus of the RBAC changed with the UPV, the maximum aggregate size, compressive strength, and Young's modulus may be correlated.

In addition, RBAC exhibits some properties similar to normal concrete. Martínez-Lage et al. [70] reported that Poisson's ratio of concrete was not significantly affected by the coarse aggregate replacement level, and the experimental group values were $0.14-0.20$. Additionally, studies have 


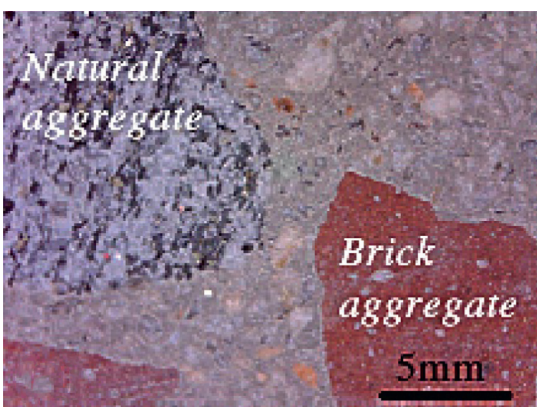

(a)

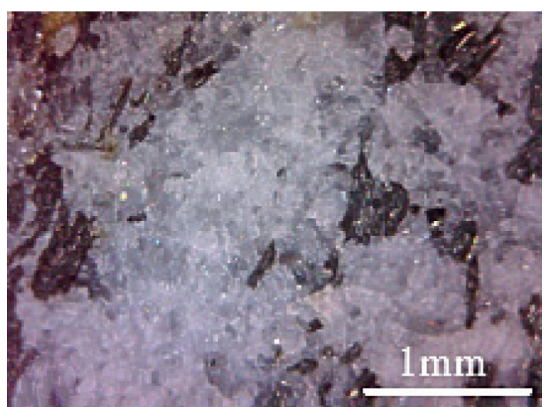

(b)

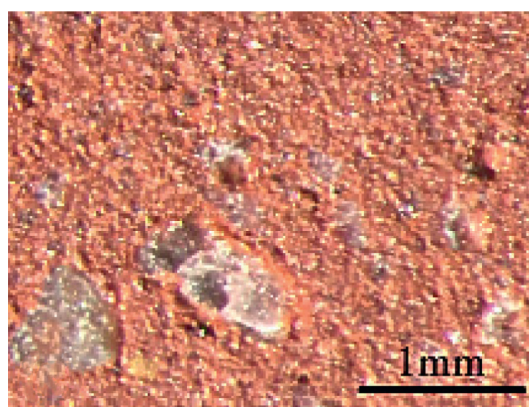

(c)

FIGURE 4: Images of the surface of concrete: (a) both natural and brick aggregates, (b) natural aggregate,and (c) brick aggregate [36].

shown that the higher the density of the RBAs is, the higher the strength of RBAC is $[37,45,71]$.

Because strength is fundamental in design, some researchers have studied the mechanical properties of RBAC. Khalaf [52] and Zong et al. [53] discovered that the compressive and flexural strengths of RBAC reduced when RBAs were used. The higher the replacement rates of RBAs are, the greater the strength loss was. The reduction in compressive strength was $44 \%$ in RBAC prepared with 50\% RBAs after 28 days. This conclusion was supported by the observations of Nepomuceno et al. [72] and Heikal et al. [38]. They revealed that the flexural and compressive strengths of concrete reduced as the brick replacement level increased. The interface between the mortar and aggregates is shown in Figure 5. As shown, RBAC contained microcracks in the ITZs, and a few internal voids appeared in the RBAs. This may have contributed to the compressive strength of RBAC being lower than that of normal concrete [60].

Although some studies have shown decreased compressive strength of RBAC, Adamson et al. [36] reported that the average strength of cylinders containing RBAs was slightly higher than that of the control mixture, and the strength increased with the brick content. They speculated that it may be due to the relatively low strength of natural aggregates compared to that of RBAs used in the experiment. In addition, the surface roughness and angular shape of RBAs contributed to the formation of a good bond between the aggregates, thereby increasing the splitting tensile strength of the geopolymer [37]. Uddin et al. [68] revealed that the splitting tensile strength of concrete decreased with an increase in the maximum aggregate size, regardless of the variation of sand to total aggregate volume (s/a) ratio and cement content. However, the results showed that the compressive strength of concrete increased with the increase in maximum aggregate size only under certain conditions. On the contrary, some studies showed that the particle size of CBP had no significant effect on the flexural strength of RBAC $[39,45,58,62]$.

Owing to the high porosity of RBAs, the elastic modulus of RBAC is lower than that of normal concrete $[45,48,58,70]$. Debieb and Kenai [19] discovered that the modulus of elasticity reduced by of $30 \%, 40 \%$, and $50 \%$ for coarse, fine, and both coarse and fine crushed brick concrete, respectively. Furthermore, Zhang and Zong [58] and

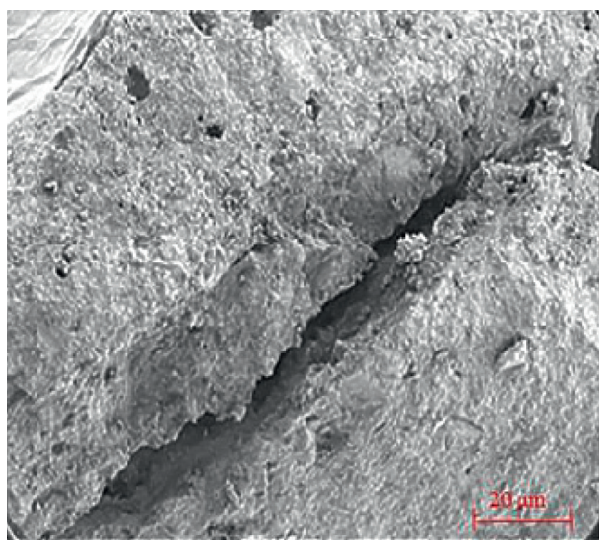

FIGURE 5: SEM image of specimen: RBA1-100 (w/c=0.55) [60]. RBA-recycled clay brick aggregate, $1-\mathrm{w} / \mathrm{c}=0.55,100$-replacement level $=100 \%$.

Aliabdo et al. [23] concluded that the presence of RBAs reduced the modulus of elasticity and splitting tensile strength of concrete. However, Disfani et al. [73] showed that the modulus of rupture and flexural modulus for all cement-stabilised blends were satisfactory, complying with the road authority requirements for pavement base applications.

Additionally, the alkali reactivity of RBA has been studied. Bektaş [51] confirmed that RBAs exhibited alkali reactivity, and the formation of ASR gel was confirmed by visual observations and microscope studies. An ettringite band formed around limestone particles was observed under a microscope. Rovnaník et al. [31] revealed that high-alkali concrete mixes with brick aggregates demonstrated higher expansions compared with the control mix.

With regard to the drying shrinkage, a few researchers revealed higher shrinkage strains in concrete containing recycled clay brick with fine and coarse aggregates $[19,74]$. This may have been due to the lower restraining effect of brick aggregates compared with that of natural aggregates. Debieb and Kenai [19] observed that the early shrinkage rate of recycled brick fine aggregate concrete was six times that of normal concrete. Furthermore, some findings on the factors affecting drying shrinkage have been reported. Khatib [74] reported that a recycled fine brick aggregate replacement level of up to $100 \%$ exhibited only a $10 \%$ shrinkage, that is, 
even a high replacement level did not result in strength reduction. Because of the internal curing effect and the dilution of CBP, replacing cement with CBP can significantly reduce the autogenous shrinkage of concrete [45].

3.4. Durability of RBAC. The durability of concrete must be considered when designing structures. It is affected by the permeability of the material used. In fact, the water permeability could be almost doubled when incorporating RBAC [19]. Apart from increased water permeability, an increase in the air permeability of concrete by using RBAs has been discovered by Zong et al. [53]. This was attributed to the more porous characteristics of RBAs.

Although water permeability has negative effects on the freezing and thawing resistances of concrete [40], Adamson et al. [36] discovered that no samples failed within 300 cycles of the freeze-thaw tests. With the increase in the replacement rate of the RBAs, the frost-thaw resistance of concrete improved $[45,75]$. Additionally, RBAC produced with RBAs exhibited a lower carbonation resistance and higher water permeability [53, 58, 76]. On the contrary, Gu [77] discovered that brick aggregate replacement had no significant negative effect on carbonation depth. In addition, according to Adamson et al. [36], by increasing the content of brick, the resistance to chloride penetration decreased. This could be attributed to higher porosity and absorption in brick aggregates compared with those in natural aggregates. Nevertheless, Ge et al. [45] revealed that concrete's resistance to chloride ion penetration improved. Furthermore, corrosion of steel in samples containing RBA initiated earlier than that in samples with natural aggregates; the existence of RBAs accelerated the corrosion of steel reinforcement $[36,53,66]$.

In addition, as the porosity of RBA itself is reflected directly on the global porosity of concrete, the RBAC demonstrated lower thermal conductivity and better fire performance. Wongsa et al. [37] revealed that the thermal conductivity and UPV of RBAC increased as the concrete density increased and that the thermal conductivity of RBAC was approximately three times lower than that of normal concrete. Furthermore, the concrete with RBAs showed slightly higher fire resistance than normal concrete $[23,57,78]$. Moreover, the presence of RBAs to produce lightweight high-calcium flies ash geopolymer concrete yielded excellent thermal insulation and good density $[37,79]$.

\section{Structural Performance of RBAC}

The RBA products used in the structure are our primary concern. Therefore, studies regarding the structural performance of RBAC are necessary. Owing to the low density of brick aggregates, the block with RBAs was much lighter and can reduce the weight of the structure. The mechanical properties of RBAC beams and columns are studied.

4.1. RBAC Masonry Units. Studies regarding concrete masonry units have been performed. The use of RBAs as an alternative to aggregates can reduce the weight of the units.
The test results of Aliabdo et al. [23] showed that the complete replacement of fine and coarse aggregates with RBAs reduced the compressive strength of the units. The dry unit weight of concrete masonry units decreased by approximately $25 \%$. The water absorption of concrete masonry units increased with the increase in the content of RBAs. With the increase in RBAs, the thermal resistance of masonry concrete units improved significantly. Therefore, compared with natural aggregates, modified concrete masonry blocks demonstrate better thermal properties. They suggested that the replacement level of coarse aggregates should not exceed 50\%; otherwise it would lead to a significant decline in compressive strength. As $20 \%$ fly ash was used to replace cement and 3\% bubble was added in renewable brick aggregate concrete, the compressive strength of the specimens reached $19.4 \mathrm{MPa}$, thereby satisfying the requirements of load-bearing blocks; furthermore, the thermal conductivity was lower than that of normal concrete [80]. MU5 RBA block was studied; the size of the specimen was $390 \mathrm{~mm} \times 190 \mathrm{~mm} \times 190 \mathrm{~mm}$, with a $57 \%$ pore rate. The results showed that the average compressive strength of the MU5 RBA block was 6\% 12\% lower than the calculated value of China standard formula. Additionally, the average flexural strength of the MU5 RBA block was $1.15 \mathrm{MPa}$, which satisfied the requirements of the test material. This block can be used in practice [81]. Zhan [82] reported that a block containing RBAs had higher water, carbonisation, and frost resistances.

Furthermore, waste clay bricks were used directly as half scale or full scale to build walls. The effects of scale on the masonry compressive strength, Young's modulus, shear modulus, and diagonal tensile strength based on component and material testing at two scales were studied. The results showed that the shear failure of the walls was affected by the diagonal tensile strength, axial load, and material properties (coefficient of friction and cohesion), and the flexural failure of the specimens was controlled by the aspect and axial load ratios [71].

4.2. RBAC Column and Beam. The performances of columns and beams containing RBAs were studied. Wang et al. [83] studied the seismic performance of columns with RBAs. Four columns were used; they exhibited natural aggregates, recycled concrete, RBAs, and fibre and silicon powder added in RBAs, respectively. They discovered that the seismic resistance of the three recycled concrete columns decreased compared with the normal concrete column. However, the addition of silica powder and fibre improved the elastic modulus and ductility. Liu et al. [84] revealed that the use of steel tubes improved the bearing capacity of columns. Ji et al. [85] and Wang et al. [86] observed the bending and shear properties of RBA beams; they reported that the specimens exhibited the similar damage form compared with normal concrete and that the reinforcing steel bar and concrete were bonded well. In addition, FRP-confined square plain concrete columns with RBAs were studied, and RBAC exhibited a lower stiffness than normal concrete; furthermore, confined RBAC columns showed higher ultimate loads and axial strains, indicating their stronger ductility [87-89]. 


\section{Conclusions}

The potential use of waste clay brick as a binder and aggregate substitute in mortar and concrete was summarised in this article. The pozzolanic activity of CBP allowed CBP to partially replace cement for the production of mortar. RBAs could be used to produce RBAC, even though the mechanical properties of RBAC were worse than those of normal concrete. The addition of RBAs improved the durability of RBAC in some cases. Furthermore, RBAC could reduce transportation costs and dead loads, and it could be used for the production of units, beams, and columns.

Completely replacing natural aggregates with RBAs has been shown to be feasible; it could reduce the consumption of natural resources and encourage the reuse of construction waste. As the structural performance of RBAC is important for constructional engineering, the application of RBAC in structures can be strengthened.

\section{Conflicts of Interest}

The authors declare that they have no conflicts of interest.

\section{Acknowledgments}

This work was funded by the Project of the Shaanxi Province Key Research and Development Program on Industry Innovation Chain (2018ZDCXL-SF-03-03-01) and the National Natural Science Foundation of China (51878552).

\section{References}

[1] A. Rao, K. N. Jha, and S. Misra, "Use of aggregates from recycled construction and demolition waste in concrete," Resources, Conservation and Recycling, vol. 50, no. 1, pp. 7181, 2007.

[2] Z. Xiao, T.-C. Ling, S.-C. Kou, Q. Wang, and C.-S. Poon, "Use of wastes derived from earthquakes for the production of concrete masonry partition wall blocks," Waste Management, vol. 31, no. 8, pp. 1859-1866, 2011.

[3] S. Manfredi, R. Pant, D. W. Pennington, and A. Versmann, "Supporting environmentally sound decisions for waste management with LCT and LCA," The International Journal of Life Cycle Assessment, vol. 16, no. 9, pp. 937-939, 2011.

[4] M. F. España, Actualización del Catálogo de Residuos Utilizables en Construcción, 2010.

[5] R. A. Robayo Salazar, P. E. Mattey Centeno, Y. F. Silva Urrego, D. M. Burgos Galindo, and S. Delvasto Arjona, "Construction and demolition wastes: analysis of its management and reuse in Cali," Revista Tecnura, vol. 19, no. 44, pp. 157-170, 2015.

[6] M. Lennon, Recycling Construction and Demolition Wastes: A Guide for Architects and Contractors, Commonwealth of Massachusetts, Department of Environmental Protection, Boston, MA, USA, 2005.

[7] I. Zabalza Bribián, A. Valero Capilla, and A. Aranda Usón, "Life cycle assessment of building materials: comparative analysis of energy and environmental impacts and evaluation of the eco-efficiency improvement potential," Building and Environment, vol. 46, no. 5, pp. 1133-1140, 2011.

[8] A. A. Shakir, S. Naganathan, and K. N. B. Mustapha, "Effect of quarry dust and billet scale additions on the properties of fly ash bricks," Iranian Journal of Science and Technology-
Transactions of Civil Engineering, vol. 38, no. C1, pp. 51-60, 2014.

[9] S. Mindess, J. F. Young, and D. Darwin, Concrete, Prentice Hall, Upper Saddle River, NJ, USA, 2nd edition, 2003.

[10] C. Chao, "Resource depletion and environmental discharge of cement production in China," Journal of Anhui Agricultural Sciences, vol. 35, no. 28, p. 8986, 2008.

[11] General Administration of Customs of the People's Republic of China, 2015.

[12] S. Jewell and S. M. Kimball, "Mineral commodity summaries 2015,” U.S. Geological Survey 2015, vol. 9, p. 196, 2015.

[13] E. C. Directive, "Directive 2008/98/EC of the European parliament and of the council of 19 November 2008 on waste and repealing certain directives," Official Journal of the European Union, vol. 312, no. 3, pp. 3-30, 2008.

[14] EU Commission, Roadmap to a Resource Efficient Europe, European Commission, Brussels, Belgium, 2011.

[15] M. Bravo, J. de Brito, J. Pontes, and L. Evangelista, "Mechanical performance of concrete made with aggregates from construction and demolition waste recycling plants," Journal of Cleaner Production, vol. 99, pp. 59-74, 2015.

[16] A. Devenny and F. M. Khalaf, "Use of crushed brick as coarse aggregate in concrete," Masonry International, vol. 12, no. 3, pp. 81-84, 1999.

[17] T. C. Hansen, Recycling of Demolished Concrete and Masonry, E And FN Spon, New York, NY, USA, 1992.

[18] F. M. Khalaf and A. S. DeVenny, "Recycling of demolished masonry rubble as coarse aggregate in concrete: review," Journal of Materials in Civil Engineering, vol. 16, no. 4, pp. 331-340, 2004.

[19] F. Debieb and S. Kenai, "The use of coarse and fine crushed bricks as aggregate in concrete," Construction and Building Materials, vol. 22, no. 5, pp. 886-893, 2008.

[20] V. Letelier, J. Ortega, P. Muñoz, E. Tarela, and G. Moriconi, "Influence of waste brick powder in the mechanical properties of recycled aggregate concrete," Sustainability, vol. 10, no. 4, p. 1037, 2018.

[21] J. M. Ortega, V. Letelier, C. Solas, G. Moriconi, M. Á. Climent, and I. Sánchez, "Long-term effects of waste brick powder addition in the microstructure and service properties of mortars," Construction and Building Materials, vol. 182, pp. 691-702, 2018.

[22] P. K. Mehta and P. J. M. Monteiro, Concrete: Microstructure, Properties, and Materials, McGraw-Hill Education, New York, Ny, USA, 2017.

[23] A. A. Aliabdo, A.-E. M. Abd-Elmoaty, and H. H. Hassan, "Utilization of crushed clay brick in concrete industry," Alexandria Engineering Journal, vol. 53, no. 1, pp. 151-168, 2014.

[24] M. S. Kirgiz, "Strength gain mechanisms of blended-cements containing marble powder and brick powder," KSCE Journal of Civil Engineering, vol. 19, no. 1, pp. 165-172, 2015.

[25] R. D. Toledo Filho, J. P. Gonçalves, B. B. Americano, and E. M. R. Fairbairn, "Potential for use of crushed waste calcined-clay brick as a supplementary cementitious material in Brazil," Cement and Concrete Research, vol. 37, no. 9, pp. 1357-1365, 2007.

[26] J. P. Gonçalves, L. M. Tavares, R. D. Toledo Filho, and E. M. R. Fairbairn, "Performance evaluation of cement mortars modified with metakaolin or ground brick," Construction and Building Materials, vol. 23, no. 5, pp. 1971-1979, 2009.

[27] E. Navrátilová and P. Rovnaníková, "Pozzolanic properties of brick powders and their effect on the properties of modified 
lime mortars," Construction and Building Materials, vol. 120, pp. 530-539, 2016.

[28] N. R. Rakhimova and R. Z. Rakhimov, "Alkali-activated cements and mortars based on blast furnace slag and red clay brick waste," Materials \& Design, vol. 85, no. 11, pp. 324-331, 2015.

[29] R. A. Robayo, A. Mulford, J. Munera, and R. Mejía de Gutiérrez, "Alternative cements based on alkali-activated red clay brick waste," Construction and Building Materials, vol. 128, pp. 163-169, 2016.

[30] L. Reig, M. M. Tashima, M. V. Borrachero, J. Monzó, C. R. Cheeseman, and J. Payá, "Properties and microstructure of alkali-activated red clay brick waste," Construction and Building Materials, vol. 43, pp. 98-106, 2013.

[31] P. Rovnaník, B. Řezník, and P. Rovnaníková, "Blended alkaliactivated fly ash/brick powder materials," Procedia Engineering, vol. 151, pp. 108-113, 2016.

[32] M. O'Farrell, S. Wild, and B. B. Sabir, "Pore size distribution and compressive strength of waste clay brick mortar," Cement and Concrete Composites, vol. 23, no. 1, pp. 81-91, 2001.

[33] S. Liu, R. Dai, K. Cao, and Z. Gao, "The role of sintered clay brick powder during the hydration process of cement pastes," Iranian Journal of Science and Technology, Transactions of Civil Engineering, vol. 41, no. 2, pp. 159-165, 2017.

[34] S. Boukour and M. L. Benmalek, "Performance evaluation of a resinous cement mortar modified with crushed clay brick and tire rubber aggregate," Construction and Building Materials, vol. 120, pp. 473-481, 2016.

[35] H. Binici, S. Kapur, J. Arocena, H. Kaplan, and H. Kaplan, "The sulphate resistance of cements containing red brick dust and ground basaltic pumice with sub-microscopic evidence of intra-pore gypsum and ettringite as strengtheners," Cement and Concrete Composites, vol. 34, no. 2, pp. 279-287, 2012.

[36] M. Adamson, A. Razmjoo, and A. Poursaee, "Durability of concrete incorporating crushed brick as coarse aggregate," Construction and Building Materials, vol. 94, pp. 426-432, 2015.

[37] A. Wongsa, V. Sata, P. Nuaklong, and P. Chindaprasirt, "Use of crushed clay brick and pumice aggregates in lightweight geopolymer concrete," Construction and Building Materials, vol. 188, pp. 1025-1034, 2018.

[38] M. Heikal, K. M. Zohdy, and M. Abdelkreem, "Mechanical, microstructure and rheological characteristics of high performance self-compacting cement pastes and concrete containing ground clay bricks," Construction and Building Materials, vol. 38, pp. 101-109, 2013.

[39] M. Nematzadeh, J. Dashti, and B. Ganjavi, "Optimizing compressive behavior of concrete containing fine recycled refractory brick aggregate together with calcium aluminate cement and polyvinyl alcohol fibers exposed to acidic environment," Construction and Building Materials, vol. 164, pp. 837-849, 2018.

[40] K. Jankovic, D. Bojovic, D. Nikolic, L. Loncar, and Z. Romakov, "Frost resistance of concrete with crushed brick as aggregate," Facta Universitatis-Series: Architecture and Civil Engineering, vol. 8, no. 2, pp. 155-162, 2010.

[41] P. Rovnaníková, Plasters, Society for Monument Protection Techniques, Prague, Czech Republic, 2002.

[42] C. Shi and R. L. Day, "Pozzolanic reaction in the presence of chemical activators: part II-reaction products and mechanism," Cement and Concrete Research, vol. 30, no. 4, pp. 607-613, 2000.
[43] J. Cabrera and M. F. Rojas, "Mechanism of hydration of the metakaolin-lime-water system," Cement and Concrete Research, vol. 31, no. 2, pp. 177-182, 2001.

[44] A. Gameiro, A. Santos Silva, R. Veiga, and A. Velosa, "Hydration products of lime-metakaolin pastes at ambient temperature with ageing," Thermochimica Acta, vol. 535, pp. 36-41, 2012.

[45] Z. Ge, Y. Wang, R. Sun, X. Wu, and Y. Guan, "Influence of ground waste clay brick on properties of fresh and hardened concrete," Construction and Building Materials, vol. 98, pp. 128-136, 2015.

[46] M. F. Rojas, "Study of hydrated phases present in a MK-lime system cured at $60^{\circ} \mathrm{C}$ and 60 months of reaction," Cement and Concrete Research, vol. 36, no. 5, pp. 827-831, 2006.

[47] F. Bektas, K. Wang, and H. Ceylan, "Effects of crushed clay brick aggregate on mortar durability," Construction and Building Materials, vol. 23, no. 5, pp. 1909-1914, 2009.

[48] A. Mobili, C. Giosuè, V. Corinaldesi, and F. Tittarelli, "Bricks and concrete wastes as coarse and fine aggregates in sustainable mortars," Advances in Materials Science and Engineering, vol. 2018, Article ID 8676708, 11 pages, 2018.

[49] L. G. Li, Z. Y. Zhuo, J. Zhu, and A. K. H. Kwan, “Adding ceramic polishing waste as paste substitute to improve sulphate and shrinkage resistances of mortar," Powder Technology, vol. 362, pp. 149-156, 2020.

[50] L. G. Li, Z. Y. Zhuo, A. K. H. Kwan, T. S. Zhang, and D. G. Lu, "Cementing efficiency factors of ceramic polishing residue in compressive strength and chloride resistance of mortar," Powder Technology, vol. 367, pp. 163-171, 2020.

[51] F. Bektaş, "Alkali reactivity of crushed clay brick aggregate," Construction and Building Materials, vol. 52, pp. 79-85, 2014.

[52] F. M. Khalaf, "Using crushed clay brick as coarse aggregate in concrete," Journal of Materials in Civil Engineering, vol. 18, no. 4, pp. 518-526, 2006.

[53] L. Zong, Z. Fei, and S. Zhang, "Permeability of recycled aggregate concrete containing fly ash and clay brick waste," Journal of Cleaner Production, vol. 70, pp. 175-182, 2014.

[54] S. I. Ahmad and M. A. Hossain, "Water permeability characteristics of normal strength concrete made from crushed clay bricks as coarse aggregate," Advances in Materials Science and Engineering, vol. 2017, Article ID 7279138, 9 pages, 2017.

[55] J. S. González, F. L. Gayarre, C. L.-C. Pérez, P. S. Ros, and M. A. S. López, "Influence of recycled brick aggregates on properties of structural concrete for manufacturing precast prestressed beams," Construction and Building Materials, vol. 149, pp. 507-514, 2017.

[56] F. M. Khalaf and A. S. DeVenny, "Properties of new and recycled clay brick aggregates for use in concrete," Journal of Materials in Civil Engineering, vol. 17, no. 4, pp. 456-464, 2005.

[57] F. M. Khalaf and A. S. Devenny, "Performance of brick aggregate concrete at high temperatures," Journal of Materials in Civil Engineering, vol. 16, no. 6, pp. 556-565, 2004.

[58] S. Zhang and L. Zong, "Properties of concrete made with recycled coarse aggregate from waste brick," Environmental Progress \& Sustainable Energy, vol. 33, no. 4, pp. 1283-1289, 2013.

[59] T. K. Šipoš, I. Miličević, and R. Siddique, "Model for mix design of brick aggregate concrete based on neural network modelling," Construction and Building Materials, vol. 148, pp. 757-769, 2017.

[60] C. Zheng, C. Lou, G. Du, X. Li, Z. Liu, and L. Li, "Mechanical properties of recycled concrete with demolished waste 
concrete aggregate and clay brick aggregate," Results in Physics, vol. 9, pp. 1317-1322, 2018.

[61] Z. Zhang, Y. Zhang, C. Yan, and Y. Liu, "Influence of crushing index on properties of recycled aggregates pervious concrete," Construction and Building Materials, vol. 135, pp. 112-118, 2017.

[62] Z. Ge, Z. Gao, R. Sun, and L. Zheng, "Mix design of concrete with recycled clay-brick-powder using the orthogonal design method," Construction and Building Materials, vol. 31, pp. 289-293, 2012.

[63] P. B. Cachim, "Mechanical properties of brick aggregate concrete," Construction and Building Materials, vol. 23, no. 3, pp. 1292-1297, 2009.

[64] M. S. Islam and M. A. A. Siddique, "Behavior of low grade steel fiber reinforced concrete made with fresh and recycled brick aggregates," Advances in Civil Engineering, vol. 2017, Article ID 1812363, 14 pages, 2017.

[65] A. Naceri and M. C. Hamina, "Use of waste brick as a partial replacement of cement in mortar," Waste Management, vol. 29, no. 8, pp. 2378-2384, 2009.

[66] T. Manzur, B. Baten, M. J. Hasan, H. Akter, A. Tahsin, and K. M. A. Hossain, "Corrosion behavior of concrete mixes with masonry chips as coarse aggregate," Construction and Building Materials, vol. 185, pp. 20-29, 2018.

[67] L. G. Li, J. J. Feng, J. Zhu, S. H. Chu, and A. K. H. Kwan, "Pervious concrete: effects of porosity on permeability and strength," Magazine of Concrete Research, pp. 1-35, 2019.

[68] M. T. Uddin, A. H. Mahmood, M. R. I. Kamal, S. M. Yashin, and Z. U. A. Zihan, "Effects of maximum size of brick aggregate on properties of concrete," Construction and Building Materials, vol. 134, pp. 713-726, 2017.

[69] T. U. Mohammed and A. H. Mahmood, "Effects of maximum aggregate size on UPV of brick aggregate concrete," Ultrasonics, vol. 69, pp. 129-136, 2016.

[70] I. Martínez-Lage, F. Martínez-Abella, C. Vázquez-Herrero, and J. L. Pérez-Ordóñez, "Properties of plain concrete made with mixed recycled coarse aggregate," Construction and Building Materials, vol. 37, no. 3, pp. 171-176, 2012.

[71] C. L. Knox, D. Dizhur, and J. M. Ingham, "Experimental study on scale effects in clay brick masonry prisms and wall panels investigating compression and shear related properties," Construction and Building Materials, vol. 163, pp. 706-713, 2018.

[72] M. C. S. Nepomuceno, R. A. S. Isidoro, and J. P. G. Catarino, "Mechanical performance evaluation of concrete made with recycled ceramic coarse aggregates from industrial brick waste," Construction and Building Materials, vol. 165, pp. 284-294, 2018.

[73] M. M. Disfani, A. Arulrajah, H. Haghighi, A. Mohammadinia, and S. Horpibulsuk, "Flexural beam fatigue strength evaluation of crushed brick as a supplementary material in cement stabilized recycled concrete aggregates," Construction and Building Materials, vol. 68, no. 5, pp. 667-676, 2014.

[74] J. M. Khatib, "Properties of concrete incorporating fine recycled aggregate," Cement and Concrete Research, vol. 35, no. 4, pp. 763-769, 2005.

[75] K. Jankovic, D. Nikolic, and D. Bojovic, "Concrete paving blocks and flags made with crushed brick as aggregate," Construction and Building Materials, vol. 28, no. 1, pp. 659663, 2012.

[76] K. S. Baek and Y. S. Kim, "A study on the carbonation resistance of concrete using crushed clay bricks as coarse aggregate," Journal of the Regional Association of Architectural Institute of Korea, vol. 10, no. 4, pp. 233-240, 2008.
[77] Y. Gu, "Research on the application of recycled aggregates from waste brick in concrete," Master's thesis, Anhui Jianzhu University, Hefei, China, 2015.

[78] A. Baradaran-Nasiri and M. Nematzadeh, "The effect of elevated temperatures on the mechanical properties of concrete with fine recycled refractory brick aggregate and aluminate cement," Construction and Building Materials, vol. 147, pp. 865-875, 2017.

[79] L. Zhu, J. Dai, G. Bai, and F. Zhang, "Study on thermal properties of recycled aggregate concrete and recycled concrete blocks," Construction and Building Materials, vol. 94, pp. 620-628, 2015.

[80] L. Wu, J. Yao, S. Gao, X. Zhu, B. Zhou, and X. Xu, "Research on factors affecting physical and mechanical properties of pre -placed concrete slabs with recycled brick aggregate manufactured by grouting," Journal of Water Resources and Architectural Engineering, vol. 13, no. 6, pp. 214-220, 2015, in Chinese.

[81] W. Cao, L. Huang, Q. T. Gao, T. Bao, F. Li, and Y. Li, "Experimental study on the basic mechanical properties of recycled brick aggregate masonry," Journal of Railway Science and Engineering, vol. 16, no. 2, pp. 114-120, 2019, in Chinese.

[82] N. Zhan, "Experimental research on durability of crushed bricks as aggregate in recycled concrete wall bricks," Master's thesis, Anhui Jianzhu University, Hefei, China, 2016.

[83] S. Wang, T. Yang, and T. Li, "An experimental research on regenerated brick granules effect on seismic behavior of recycled concrete columns," Industrial Construction, vol. 43, no. 11, pp. 26-29, 2013.

[84] P. Liu, X. Du, J. Liang, Z. Niu, and J. Shi, "Exerimental study on short column axial compression performance of recycled aggregate concrete filled square steel tube," Journal of Agricultural University of Hebei, vol. 5, pp. 112-118, 2017, in Chinese.

[85] C. Ji, A. Zhai, W. Zhai, S. Chen, and C. Wang, "Experimental study on flexural performance of recycled brick coarse aggregate concrete beam," Hydro-science and Engineering, vol. 6, pp. 59-64, 2012, in Chinese.

[86] C. Wang, A. Zhai, S. Chen, C. Ji, and A. Zhao, "Analysis of anti-shear capacity of slope section for recycled brick aggregate concrete beam," Journal of Water Resources and Water Engineering, vol. 24, no. 2, pp. 151-154, 2013, in Chinese.

[87] B. Yan, L. Huang, L. Yan, C. Gao, and B. Kasal, "Behavior of flax FRP tube encased recycled aggregate concrete with clay brick aggregate," Construction and Building Materials, vol. 136, no. 2, pp. 265-276, 2017.

[88] L. Huang, L. Chen, L. Yan et al., "Behavior of polyester FRP tube encased recycled aggregate concrete with recycled clay brick aggregate: size and slenderness ratio effects," Construction and Building Materials, vol. 154, pp. 123-136, 2017.

[89] M. M. Islam, M. S. I. Choudhury, and A. F. M. S. Amin, "Dilation effects in FRP-confined square concrete columns using stone, brick, and recycled coarse aggregates," Journal of Composites for Construction, vol. 20, no. 1, Article ID 04015017, 2015. 